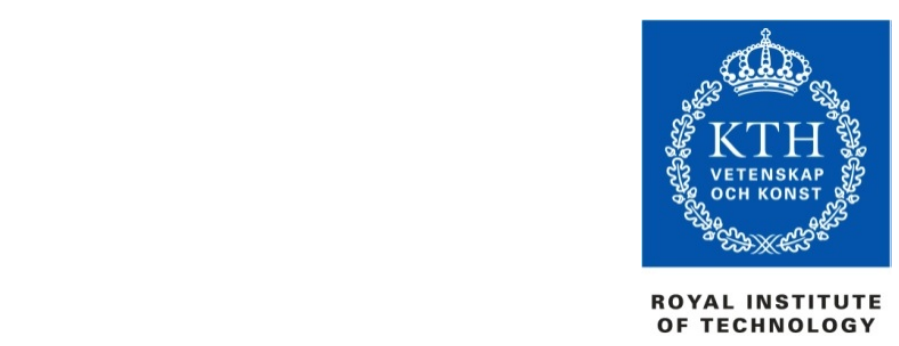

\title{
Run-around coil ventilation heat recovery system: A comparative study between different system configurations
}

\author{
Jörgen Wallin*, Hatef Madani, Joachim Claesson \\ Department of Energy Technology, Division of Applied Thermodynamics and Refrigeration \\ Royal Institute of Technology, SE-100 44 Stockholm, Sweden \\ * Phone: +46 (0)8 79086 53, Fax: +46 (0)8 2030 07, Email: jorgen.wallin@energy.kth.se
}

\begin{abstract}
:
The energy performance of buildings with considerable annual heat load is dependent on the ventilation air change rates (ACH). Buildings utilized for commercial use often have high ACH and therefore high annual heat load. In order for these buildings to have a reasonable energy performance a heat recovery system is often used to recover heat from the extraction air to the makeup air. There are different variations of these systems; one that is frequently used in Sweden is a run around coil heat recovery system.
\end{abstract}

The present paper summarizes the findings from the previous studies, and presents a comparative study, for three different cases; the traditional run-around coil heat recovery system; with a three stage on/off controlled heat pump retrofitted into the system; and with a variable capacity heat pump retrofitted into the system.

Annual modeling shows that by retrofitting a well-designed 3 stage heat pump to the system the annual heat recovery rate for the Stockholm Case can be increased from $47 \%$ to $65 \%$. For the retrofitted variable capacity heat pump the numbers for the Stockholm Case is an improvement of annual heat recovery from $47 \%$ to $66 \%$.

The modeling also shows that a well designed variable heat pump can cover $81 \%$ of the ventilation heating demand and a well designed multi stage heat pump $77 \%$ of the demand.

Keywords — Run-around coil, ventilation heat recovery, performance factors, retrofitted heat pump. 


\section{Introduction}

The energy performance of buildings with considerable annual heat load is dependent on the ventilation air change rates $(\mathrm{ACH})$. Buildings utilized for professional use often have high $\mathrm{ACH}$ and therefore high annual heat load. In order for these buildings to have a reasonable energy performance a heat recovery system is often used to recover heat from the extraction air to the makeup air. There are different variations of these systems; one that is frequently used in Sweden is a run around coil heat recovery system.

A run-around coil heat recovery system is often used in buildings where the extraction air contains volatile substances that can contaminate the supply air. Hospital buildings are one example of a building type that matches this criterion; another one is buildings that contain processing industry.

Previous studies [1, 2, 3, 4, and 5] have looked into the important factors that influence the performance of ventilation heat recovery system with a run around coil. Several factors have been identified in the previous studies; of special interest are the brine flow rate and the glycol concentration of the brine. Another study [6] has investigated the possibility to increase the rate of recovery by retrofitting a multi stage heat pump to a run around coil recovery system. The conclusion for the retrofitted heat pump study is that there is a potential for improved energy performance if the sizing of the heat pump system is correct. In the Madani et. al. [7] study the performance of a heat recovery system using variable speed heat pump together with the run around coil was modeled and analyzed.

The present paper summarizes the findings from the previous studies, and presents a comparative study, for three different cases; the traditional run-around coil heat recovery system; with a three stage on/off controlled heat pump retrofitted into the system; and with a variable capacity heat pump retrofitted into the system.

\subsection{The different system setups - Run around coil}

A run-around coil heat recovery system consists of at least two coiled heat exchangers. The coils are connected via pipes to a loop in which a fluid flows. The fluid is usually a mix of water and an antifreeze fluid. Heat is "moved" from the hot side (extraction/exhaust air) to the cold side (supply air) via the brine fluid. It is also possible to recover cooling energy during the warm days. The flow rate to the supply heat exchanger is usually controlled by a three way valve or by frequency

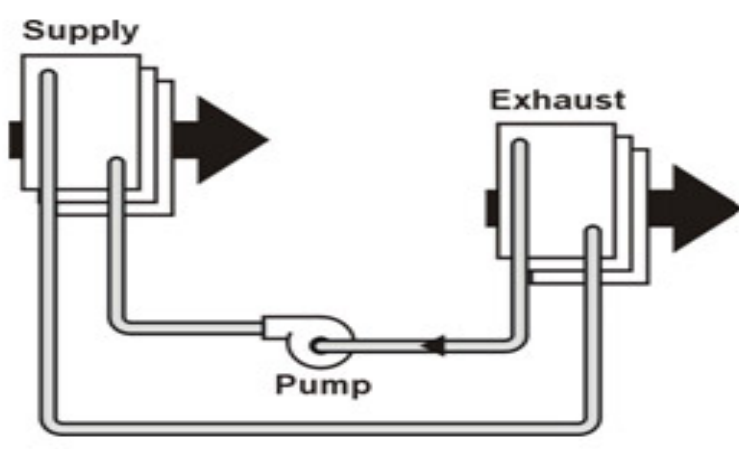

Fig. 1. Scheme of a run around coil heat recovery controlling the pump. The flow rate is controlled so that the temperature on the supply air does not exceed the desired value. The size of the heat exchangers is traditionally designed to recover around $50 \%$ of the heat when the ambient temperature is $0{ }^{\circ} \mathrm{C}$. 


\subsection{The different system setups - Run around coil and retrofitted heat pump}

A heat pump is retrofitted to the existing run around coil system, as shown in fig. 2 . Depending on the ambient temperature, the heat recovery system can be switched from run around coil to the heat pump unit and vice versa. The different routes of the brine depend on the operation mode, and are denoted 1 and 2 in the scheme.

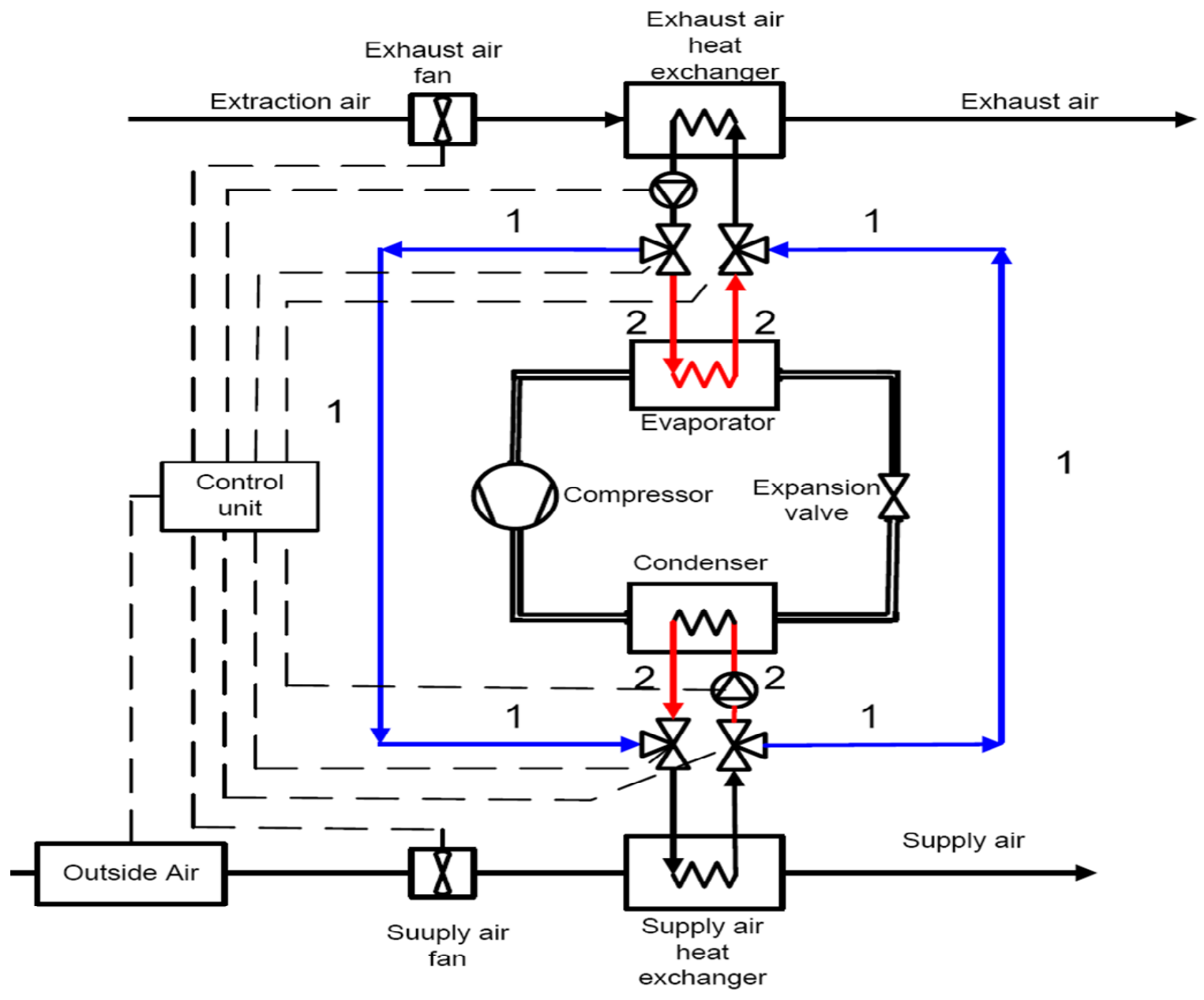

Fig. 2. Scheme of a run around coil heat recovery when the heat pump unit is retrofitted

Two different heat pumps have been evaluated, in the first case a 3 stage on/off controlled heat pump unit was evaluated, secondly the system performance was evaluated using a variable capacity heat pump. With the heat pump retrofitted it is possible to lower the temperature of the exhaust air below the ambient temperature. This fact can be used to achieve a greater recovery rate than the traditional run around coil system.

\section{Results}

In a previous study, Madani et. al [6] investigated the efficiency for an existing medium sized run around coil heat ventilation heat recovery system; air flow rate around 6-7 kg/s. Simulations pointed at a recovery rate of $47 \%$ over one full year. This model was then used to simulate the system performance with different retrofitted heat pump units. Fig. 3 shows a comparison between the annual performances of the three different system setups in two European locations. 


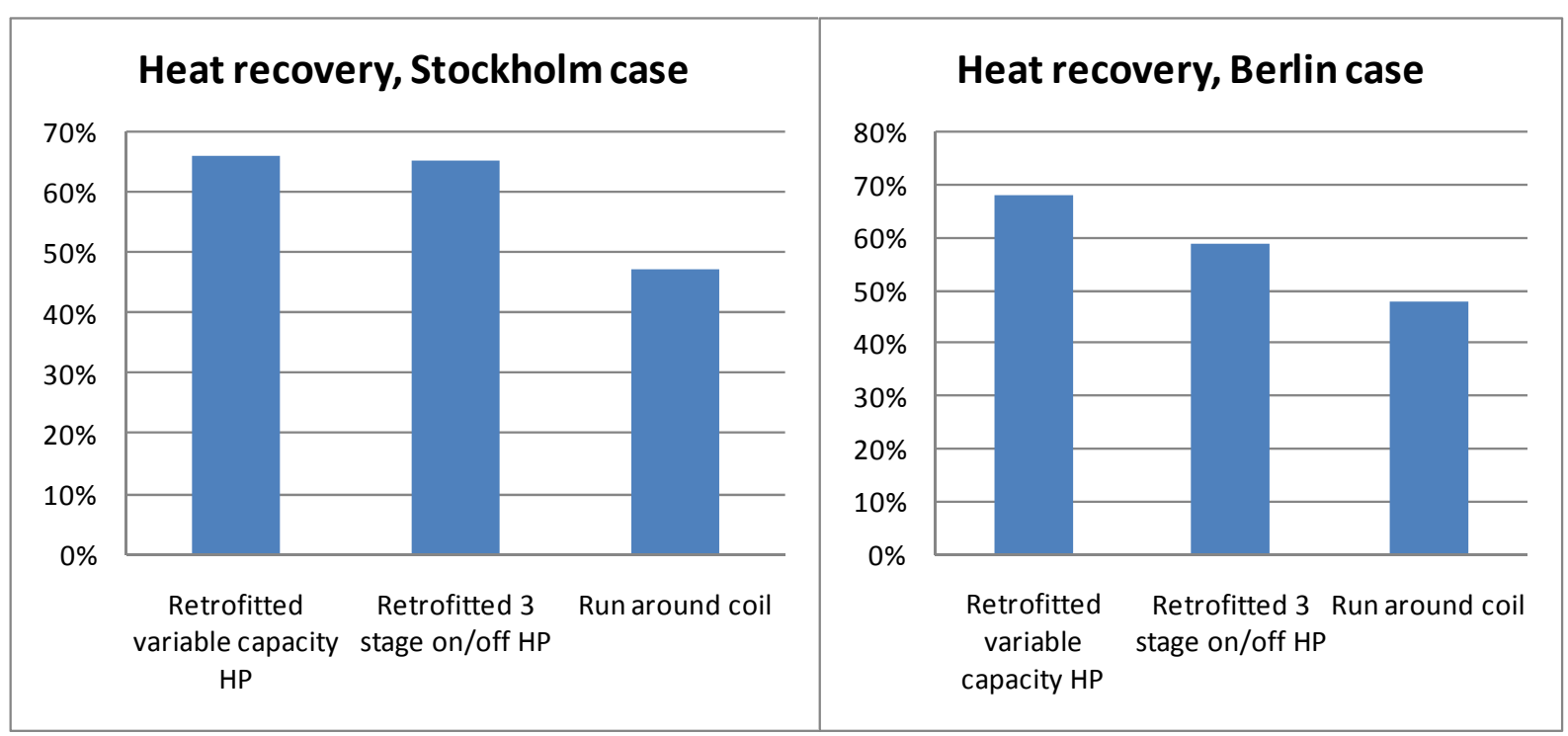

Fig. 3. Annual heat recovery for different system setups in Stockholm, Sweden and Berlin, Germany

Fig. 3. shows that the heat recovery for the system with a 3 stage heat pump and the system with the variable capacity heat pump more or less have same percentile recovery for the Stockholm Case, For Berlin Case the performance of the retrofitted 3 stage heat pump is not as efficient as the variable capacity heat pump. The reason for this is that the 3 stage heat pump is designed for the Stockholm case. The sizing of the heat pump unit is important to have a high system performance; this is especially true for the 3 stage pump [6].

Another way of looking at the system is to evaluate the total annual heating supplied by the heat pump. Fig. 4. shows how much of the total heating demand of the air handling unit that is covered by the run around and the heat pumps.

Degree of coverage for the heat pump cases is how much energy that is supplied to the air going to the building, i.e. total recovery + energy supplied to the compressor divided by the total demand of the air handling unit.

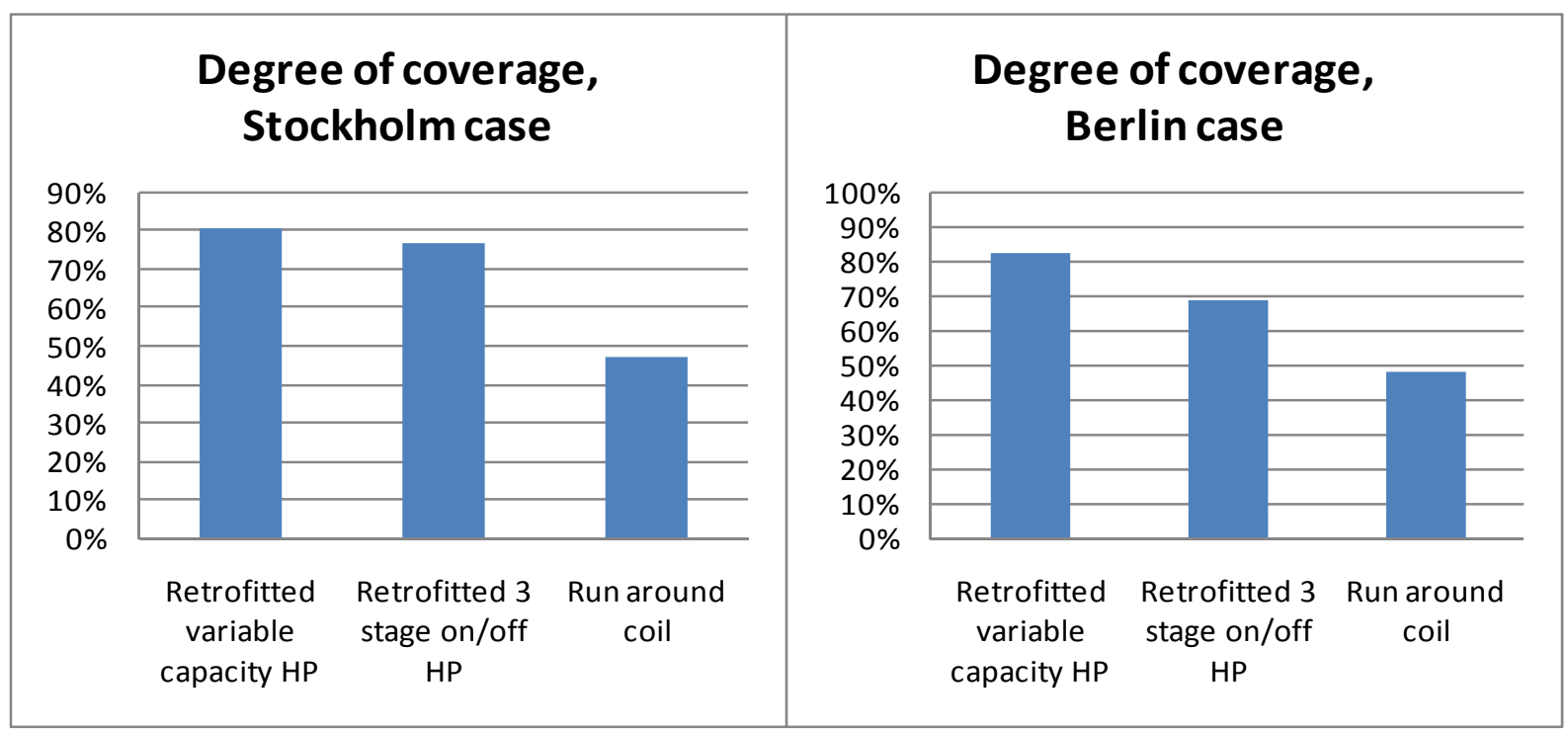

Fig. 4. Annual degree of coverage for different system setups in Stockholm, Sweden and Berlin, Germany 
You could also argue that the exhaust air temperature is a measure on how efficient the heat recovery system is, i.e. if the exhaust air temperature is the same as the ambient temperature the heat recovery would be $100 \%$. In Fig. 5 the exhaust air temperature is plotted together with the ambient temperature for the different system setups for January.

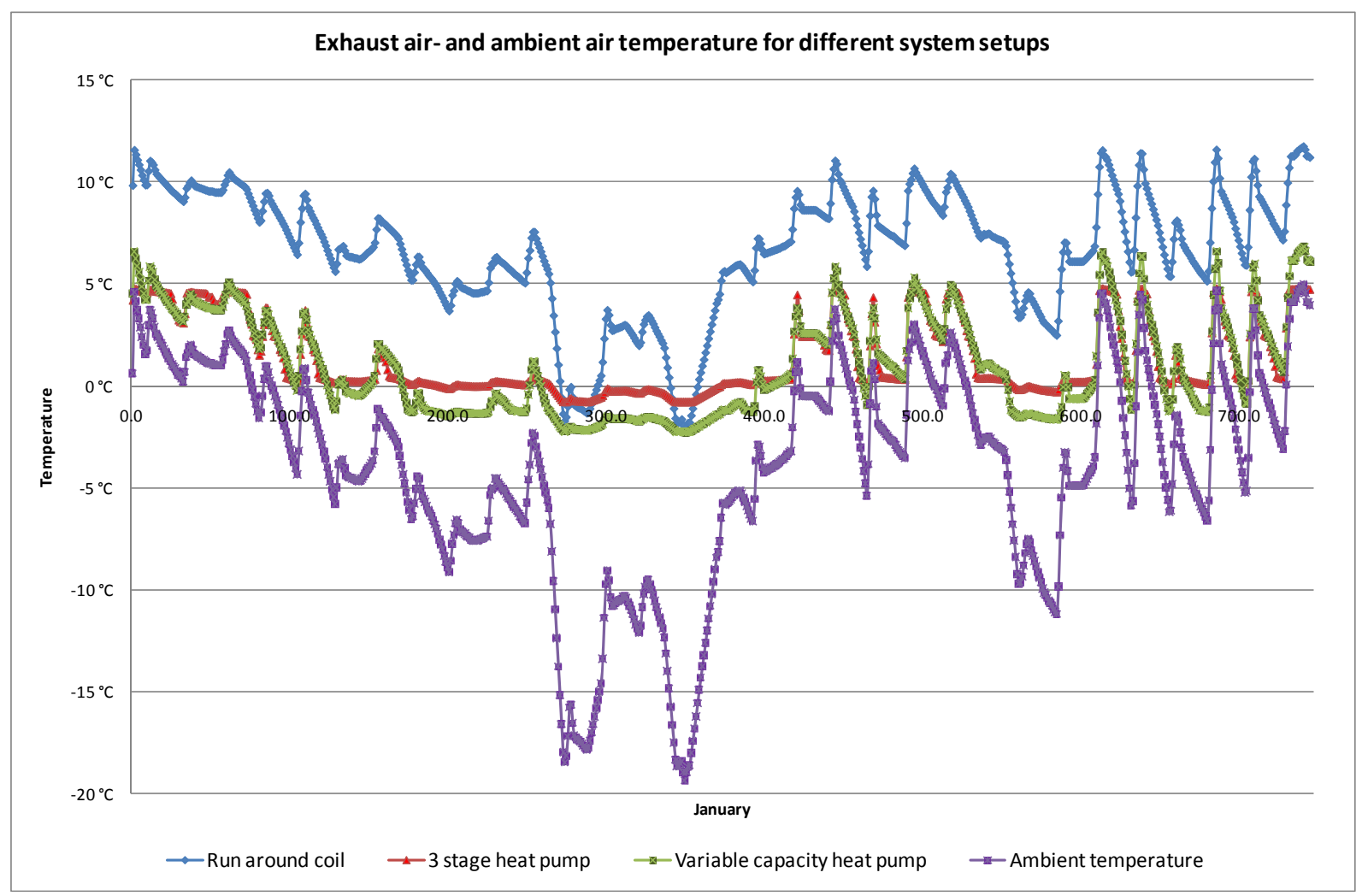

Fig. 5. Exhaust air- and ambient temperatures for different heat recovery systems in January

From Fig. 5. the improvement of the heat recovery is visible. It is also visible that there is an ambient temperature when the run around coil system is as efficient as the heat pump systems. For the 3 stage heat pump system this is around $-15{ }^{\circ} \mathrm{C}$, for the variable capacity case the temperature seem to be lower than $-18{ }^{\circ} \mathrm{C}$. However Madani et. al. concluded [7] that the variable capacity heat pump obtains its maximum heat capacity at roughly $-6{ }^{\circ} \mathrm{C}$ and from this point the supply air temperature achieved from the heat pump gradually gets closer to the one obtained from the run around coil system. With this in mind the cost of the energy to the supplementary heater becomes of interest if it is cheaper than the electricity that is supplied to the heat pump.

\section{Discussion}

The comparative study were undertaken to summarize the findings from the series of investigations regarding the possibilities to increase system performance of run around coil ventilation heat recovery systems. This is a work in progress and so far several ideas on how to increase the system performance have been identified.

The results strongly suggest that there is a potential to retrofit a heat pump to a run around coil system. There are several advantages regarding the installation of a heat pump to a system configuration such as this, the greatest one is perhaps the ease of installation. Other 
advantages include a constant source temperature and a small temperature difference during most of the operation hours which lead to an effective heat pump operation.

For the multi stage heat pump the sizing is crucial and somewhat complicated to achieve a high recovery rate, this was described by Madani H. et. al [6]. The variable capacity is more flexible in the sizing; however these heat pumps are relatively expensive.

An interesting finding is that for the Stockholm Case the variable capacity heat pump can cover $81 \%$ of the ventilation heating demand and the multi stage heat pump $77 \%$ of the demand. This fact is positive if the supplementary heater is supplied by an energy source that is more costly than the electricity to the heat pump and vice versa if the supplementary energy is cheaper.

It seems likely to achieve an acceptable economy in a retrofitting project with a variable capacity heat pump. The payback for such a project, where the air flow is $2 \mathrm{~m}^{3} / \mathrm{s}$, would roughly be around 7 years. For a well designed multi stage heat pump system the payback is shorter, because of the lower price of on/off heat pump. The payback is calculated using prices from Swedish heat pump manufacturer Nibe.

Considering the lifetime of a heat pump system it seems likely that the life cycle profit for a retrofitting project would be considerable.

In those cases where new run around coil system is built there is definitely a strong recommendation to consider a system setup incorporating a heat pump.

\section{Conclusion}

The present paper is summarizing the investigations on how to increase energy performance of a run around coil ventilation heat recovery system. Several factors that influence the performance of these systems have been identified. Investigations have also been undertaking the task of looking into how heat pump units can be retrofitted to the existing run around coil system in order to improve system performance and consequently decrease the energy use of the system.

In conclusion, the annual modeling shows that by retrofitting a well-designed 3 stage heat pump to the system the annual heat recovery rate for the Stockholm Case can be increased from $47 \%$ to $65 \%$. For the retrofitted variable capacity heat pump the numbers for the Stockholm Case is an improvement of annual heat recovery from $47 \%$ to $66 \%$.

A rough estimate of the payback time for retrofitting a heat pump to a system with a air flow of $2 \mathrm{~m}^{3} / \mathrm{s}$ would be around 7 years for the variable capacity heat pump.

\section{Acknowledgement}

This research is a part of a national research and development program in Sweden called "Effsys2". It is a four year program for applied R\&D in Refrigeration and Heat Pump Technology financed by Swedish Energy Agency and a consortium consisting of Bravida, DynaMate, Humlegården Fastigheter and Stockholm Stad. 


\section{References}

[1] Emerson W. H. 1984. "Making the most of run-around coil systems,” Heat Recovery Systems Vol. 4. No. 4. pp. 265-270.

[2] Forsyth B. I. and Besant R. W. 1988b. "The performance of a run-around heat recovery system using aqueous glycol as a coupling liquid,” ASHRAE Transactions 94(2). pp. 532-545

[3] Forsyth B. I. and Besant R. W. 1988b. "The design of a run-around heat recovery system," ASHRAE Transactions 94(2). pp. 511-531

[4] Zeng Y. Y. et. al. 1992. "The effect of temperature-dependent properties on the performance of run-around heat recovery systems using aqueous-glycol coupling fluids,” ASHRAE Transactions 98(1). pp. 551-562.

[5] Wallin J. et. al 2009. "Ventilation heat recovery with run around coil: System analysis and a study on efficiency improvement - Part I” Proceeding of ASHRAE Region-At-Large conference, Kuwait.

[6] Madani H. et. al 2009. "Ventilation heat recovery with run around coil: System analysis and a study on efficiency improvement - Part II" Proceeding of ASHRAE Region-At-Large conference, Kuwait.

[7] Madani H. et. al 2009. "Retrofitting a variable capacity heat pump to a ventilation heat recovery system: modelling and performance analysis” Proceedings of ICAE 2010, Singapore. 